\title{
Prevalence of human immunodeficiency, hepatitis B and hepatitis $C$ viruses among antenatal care attendees in Bauchi State, Nigeria
}

\author{
Dada Mansur Mustapha, ${ }^{1}$ Danladi Saba'atu Elizabeth, ${ }^{2}$ Yusuf Abdu Misau, ${ }^{2}$ \\ Mohammed Alkali, ${ }^{3}$ Onyi Titus, ${ }^{2}$ Bashir Muhammad Faruk, ${ }^{4}$ Sani Mohammed Dambam, ${ }^{2}$ \\ Iliyasu Hussaini, ${ }^{5}$ Abubakar Auwal Alami-Adhama, ${ }^{6}$ Madaki Abubakar Ibrahim ${ }^{1}$ \\ ${ }^{1}$ Bauchi State Health Contributory Management Agency; ${ }^{2}$ Department of Community Medicine, College of \\ Medical Sciences, Abubakar Tafawa Balewa University; ${ }^{3}$ Department of Internal Medicine, Abubakar \\ Tafawa Balewa University Teaching Hospital; ${ }^{4}$ Department of Pediatrics, Abubakar Tafawa Balewa \\ University Teaching Hospital; ${ }^{5}$ Bauchi State Agency for the Control of HIV/AIDS, Tuberculosis, Leprosy \\ and Malaria; ${ }^{6}$ Emergency Operation Centre, Bauchi State Primary Health Care Development Agency, \\ Bauchi, Nigeria
}

\begin{abstract}
Human Immunodeficiency Virus (HIV), Hepatitis B Virus (HBV) and Hepatitis C Virus (HCV) are blood borne viral infection with huge disease burden on pregnant women and their babies especially in Bauchi, Nigeria. Data on the prevalence rates of these infections would aid the clinical management and public health
\end{abstract}

Correspondence: Saba'atu Elizabeth Danladi, Department of Community Medicine, College of Medical Sciences, Abubakar Tafawa Balewa University Bauchi, Bauchi, Nigeria.

Tel.: +234.8037439790.

E-mail: sabaatu44@gmail.com

Key words: Hepatitis B Virus, Hepatitis C Virus, Human Immune Deficiency Virus, Ante Natal Care.

Contributions: EDS, protocol design and review, process of ethical review and clearance, data extraction checklist design, review of collated data and extraction, review of analysed data and report writing; TO, YAM, protocol design, data extraction checklist design, review of analysed data and report writing; MDS, MFB, IYH, MIA, MDM, AIM, AM, design, data extraction checklist design, review of analysed data and report writing.

Conflict of interest: the authors declare no potential conflict of interest.

Acknowledgements: the authors wish to acknowledge BACATMA and Bauchi State Health Research Ethics Committee (BSHREC) for their enormous contributions in this study.

Funding: none.

Received for publication: 12 January 2019

Revision received: 13 May 2019.

Accepted for publication: 15 June 2019.

This work is licensed under a Creative Commons Attribution NonCommercial 4.0 License (CC BY-NC 4.0).

(C) Copyright: the Author(s), 2019

Licensee PAGEPress, Italy

Annals of African Medical Research 2019; 2:65

doi:10.4081/aamr.2019.65 control of these infections. The study determined the prevalent rates of HIV, HBV and HCV among ante-natal care (ANC) attendees in health facilities in Bauchi State, north-eastern Nigeria. This is a a descriptive study that reviewed data secondarily from 13 health facilities in Bauchi State, Nigeria. Data were collected for a 12-month period from July 2017 - June 2018. The study found the following average prevalence rates among the ANC attendees: HIV $(0.71 \%)$, HBV $(1.57 \%)$ and HCV $(0.64 \%)$. The study found low but significant prevalent rates of HIV, HBV and HCV infections among the ANC attendees. The study recommends for strengthening of preventive and curatives measures against these viruses among the pregnant women. These include health education, HBV vaccination, anti-retroviral therapy and early diagnosis and treatment of these viruses. The study also recommends for appropriate, complete and consistent medical records to monitor these viruses. Further studies are required for the HIV, HBV and $\mathrm{HCV}$ infections and their co-infections among the pregnant women.

\section{Introduction}

People living with HIV/AIDS (PLWHA) are at a higher risk of developing other infections such as tuberculosis (TB), hepatitis B Virus (HBV) and hepatitis C Virus (HCV). ${ }^{1}$ This is because the immunodeficiency caused by invasion of Human Immunodeficiency Virus (HIV) decreases body's immunity by altering its ability to adequately respond to incoming infections thus increases the risk of being with pathogens that are controlled by innate and adaptive cellular immune responses and some that are controlled by phagocytic antibody responses. ${ }^{2}$ More so, Hepatitis B virus (HBV), Hepatitis C virus (HCV) and HIV are blood borne viruses with common modes of transmission. These are: through sexual contact that involve exchange of body fluid that contains significant viral load; transfusion of unscreened blood and blood products; sharing of unsterilized sharp objects and injection drug use. However, due to the shared modes of transmission, a high proportion of adults at risk for HIV infection are also at risk for HBV and HCV infections. ${ }^{3}$ The presence of HBV and $\mathrm{HCV}$ contribute to HIV-related pathogenesis and often increase viral load in HIV-infected people, ${ }^{4}$ who are at increased risk for serious, life threatening complications. ${ }^{1}$ Viral hepatitis progresses faster and cause liver-related health problems among people with $\mathrm{HIV} / \mathrm{HBV}$ and $\mathrm{HIV} / \mathrm{HCV}$. Its more than triples the risk for liver 
disease, liver failure, and liver-related death. ${ }^{5}$ The HBV, HCV and HIV has emerged as a leading cause of morbidity throughout the world in the last three decades and increased chances of opportunistic infections. ${ }^{6,7} \mathrm{HBV}$ and $\mathrm{HCV}$ infections complicates and adversely affects the clinical course of HIV in infected patients. ${ }^{7}$ Pregnant women living with HIV and infected with viral hepatitis are the category of people at greater risks due to the potential mother to child transmission of HIV. ${ }^{8}$ These infections are major leading cause of maternal death. ${ }^{9}$

Globally, as at the end of 2015, HIV accounted for 36.9 million infections. ${ }^{10}$ Chronic HBV and HCV infection affected 240 million and 184 million people respectively. ${ }^{10,11}$ An average of 1 in 10 persons living with HIV was reportedly co-infected with HBV, while about 1 in 4 people were co-infected with $\mathrm{HCV}^{5}$ WHO reports that HCV affects $2-15 \%$ and chronic HBV infection affects $5-20 \%$ of people living with HIV and AIDS (PLWHA) worldwide. ${ }^{12} \mathrm{HIV}$ HCV and HBV-HCV infections affects 2.75 million and 2.6 million people respectively and has highest disease burden in the African and South East Asia Regions. ${ }^{12}$

The HBV is endemic in Nigeria with an HBV prevalence rate of 18 million. ${ }^{13}$ More than 35 million people are infected with hepatitis B and C viruses in Nigeria. ${ }^{14,15}$ This study targeted pregnant women attending ANC at primary, secondary and tertiary health facilities in Bauchi State to obtain extensive data on the prevalence of HBV, HVC and HIV. These prevalence rates provide data to influence intervention and policy development in the clinical management and public health control of the viruses among pregnant women. Hence, the study is aimed at determining the prevalence of HBV and HCV among ANC attendees living with HIV in Bauchi State, Nigeria. Although a similar study was conducted in a tertiary hospital in Bauchi, however, the study determined the prevalence of HBV, HBC and HIV but the target population was blood donors. ${ }^{16}$ Similarly, another study conducted in the same hospital targeted pregnant women but did not determine the prevalence of HIV among them. ${ }^{17}$

The specific objectives of this study were to determine the prevalence of HIV among ANC attendees in health facilities in Bauchi State; to determine the prevalence of HBV among ANC Attendees in health facilities in Bauchi State and to determine the prevalence of HCV among ANC attendees in health facilities in Bauchi State.

\section{Materials and Methods}

\section{Study area and study sites}

The study area was Bauchi State in north- eastern Nigeria. The study site was at the Bauchi State Agency for the Control of HIV/AIDS, Tuberculosis, Leprosy and Malaria (BACATMA).

\section{Study population}

Study population consisted of pregnant women living with $\mathrm{HIV}$ and attending antenatal care services in both public and private health facilities providing HIV/AIDS services in Bauchi State.

\section{Study design}

It was a cross sectional descriptive study involving of secondary data collection from the medical records of BACATMA. The records comprised of primary, secondary and tertiary health facilities (both private and public). Data was obtained within a one-year period covering July 2017 to June 2018.

\section{Data collection}

Quantitative data was secondarily obtained from the medical record of BACATMA. The data included number of HIV, HBV and $\mathrm{HCV}$ cases among the ANC attendees in the health facilities in Bauchi State. The prevalence of HIV, HBV and HCV among the ANC attendees was determined using the method described in by center for disease control (CDC). ${ }^{17}$ Prevalence of disease $=($ all new and pre-existing cases during a given time / population during the same time period) $\times 100$.

Categorisation of endemicity of $\mathrm{HBV}$ and $\mathrm{HCV}$ infection was conducted by the method described in previous studies, ${ }^{1,17,18}$ as high (prevalence $\geq 3 \%$ ) moderate (prevalence $2-2.9 \%$ ), low (prevalence $1.0-1.9 \%$ ), and very low (prevalence $<1.0 \%$ ).

\section{Data analysis}

All data were statistically analyzed using Microsoft Excel and Statistical SPSS, Version 23.0. P value of $<0.05$ was considered statistically significant.

\section{Ethical consideration}

Approval was obtained from Bauchi State Health Research Ethics Committee (BASHREC), since it is a secondary data. Permission for the study was obtained from BACATMA. Confidentiality and anonymity of data were observed in the study.

\section{Results}

Records of 70 health facilities providing comprehensive HIV/AIDS care services were collated and analysed over a period of 12 months from July 2017 to June 2018. Only 30 (42.8\%) of the health care facilities' data were reported consistently for 12 months.

\section{Prevalence of HIV among ANC attendees in health facilities in Bauchi State}

Figure 1 shows the percentage prevalence of HIV among the ANC attendees reported in the health facilities.

The highest prevalence of $4.55 \%$ was reported in Tashan Babiye Comprehensive Health Centre (CHC) while the lowest prevalence was reported in Alkaleri Town Maternity (0.12\%). The average HIV prevalence was $0.71 \%$.

\section{Prevalence of $\mathrm{HBV}$ among ANC attendees in health facilities in Bauchi State}

Figure 2 shows the percentage prevalence of HBV among the ANC attendees in the health facilities.

From this figure, the prevalence of HBV among ANC attendees was reported only in 3 facilities namely: Remee Clinic $(2.15 \%)$, and $\mathrm{Ni}$ 'ima Consultant $(0.64 \%)$. The highest prevalence of HCV (2.15\%) among the ANC attendees was reported in Remee Clinic while the lowest $(0.64 \%)$ was reported in Ni'ima Consultant Clinic. Family Planning Clinic Kofar Wase reported a prevalence rate of $1.91 \%$. The average HBV prevalence was $1.57 \%$.

\section{Prevalence of $\mathrm{HCV}$ among $\mathrm{ANC}$ attendees in health facilities in Bauchi State}

The result of percentage prevalence of $\mathrm{HCV}$ among ANC attendees in health facilities at Bauchi State is presented in Figure 3. Only one health facility reported prevalence of HCV. This was Kofar Wase Family Planning Clinic and reported a prevalence of $0.64 \%$. 


\section{Discussion}

Hepatitis B and C viruses are serious blood borne infections that sometimes co-exist with HIV infection with enormous disease burden among pregnant women. ${ }^{21-23}$ This study examined the prevalence of HIV, HBC and HCV infections among attendees of ANC in the health facilities in Bauchi State. The study found that the prevalence of HIV among the ANC attendees in the facilities ranged from $0.12 \%$ to $4.55 \%$ with an average prevalence of $0.71 \%$. The variation of the prevalence rates among the facilities could be accounted for by the different levels of uptake of elimination of mother to child transmission of HIV and AIDS (eMTCT) services at these facilities. The average prevalence of HIV among the ANC attendees is lower than the prevalence of $5.8 \%$ reported by Chanu et al. ${ }^{24}$ However, it is higher than $0.2 \%$ reported by Mohammed et al. ${ }^{16}$ Poor medical records and poor ANC attendance could be attributed to the low rate of HIV prevalence rate among the ANC attendees in this study.

The study found an average HBV prevalence of $1.57 \%$ among the ANC Attendees. The prevalence rates ranged from $0.64 \%$ to $2.15 \%$ among the facilities. This average prevalence is comparable to the $2.9 \%$ obtained in the study conducted among pregnant women in Port Harcourt, South-southern Nigeria ${ }^{25}$. However, it is lower than $14.6 \%{ }^{17}$ and $7.0 \%{ }^{16}$ both conducted in Bauchi; $11.0 \%$ found in Makurdi in north-central Nigeria, ${ }^{23}$ and the sero-prevalence in Sub Sahara Africa (SSA) which ranges from $9 \%$ to

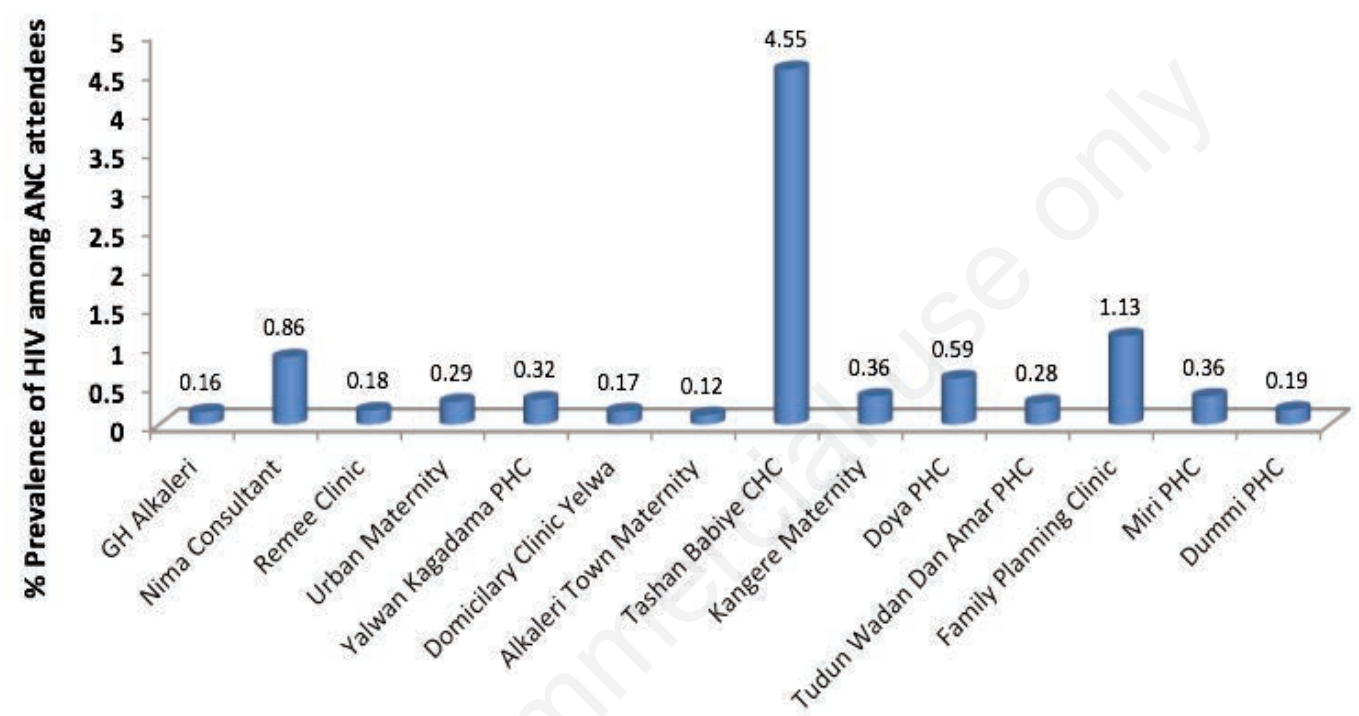

Project Facilities

Figure 1. Percentage prevalence of HIV among ANC attendees in health facilities at Bauchi State, Nigeria. Average Prevalence=0.71\%

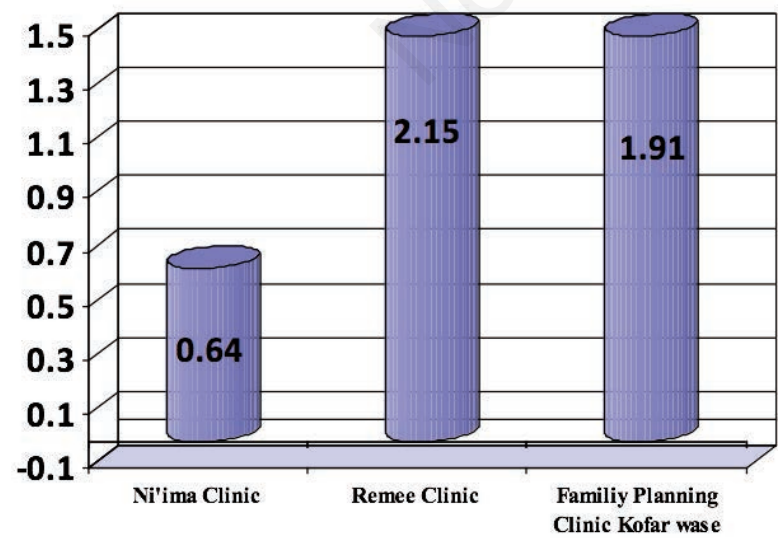

$\square$ Percentatge Prevalence of Hepatitis B Infection Among ANC Attendees

Figure 2. Percentage prevalence of HIV among ANC attendees in health facilities at Bauchi State, Nigeria. Average Prevalence $=1.57 \%$

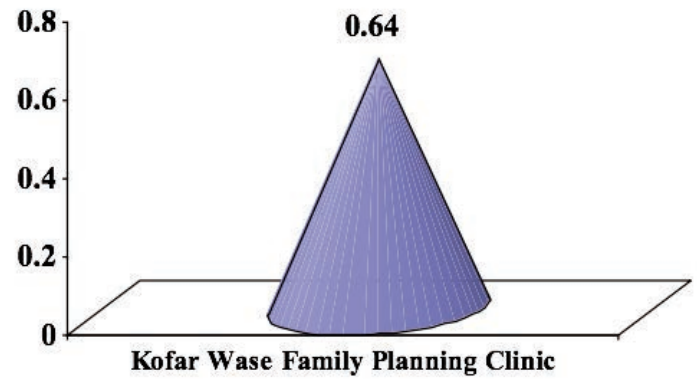

$\square$ Percentage of Hepatitis C Infection among ANC Attendees in Bauchi State

Figure 3. Percentage prevalence of HCV among ANC attendees in health facilities at Bauchi State, Nigeria. 
$20.0 \%{ }^{27}$ Other studies conducted in Nigeria that reported lower HBV prevalence rates include $7.9 \%$ and $8.2 \%$ in Abuja ${ }^{28}$ and Yola respectively. The comparatively lower prevalence of hepatitis B virus among the ANC attendees in the study could be as a result of poor uptake of eMTCT at the ANC, poor uptake of the HBV screening due to the cost of the screening and poor and incomplete medical records at the facilities.

The study found an $\mathrm{HCV}$ prevalence of $0.64 \%$ among the ANC attendees. This finding is lower than $2.0 \%{ }^{17}$ and $0.7 \%{ }^{16}$ both in Bauchi; $0.5 \%$ in Niger Delta; $301.0 \%$ in Nnewi; 31 1.4\% in Kaduna $^{24}$ and $2.3 \%{ }^{28}$ Again poor uptake of eMTCT and HCV screening and poor medical records could be implicated in the low prevalence of the HCV reported in this study.

The low prevalence rates of HIV, HBV and HCV among the participants has significant public health implications. The pregnant women could potential transmitting these viral infections to their unborn children, their husbands and even co-wives. This could lead to enormous level of morbidity and mortality to the affected people. Therefore, there is need to strengthen initiatives that prevent the transmission of these viruses. These include vaccination for HBV. ART for pregnant women; improving the uptake of HBV and HCV screening at the ANC clinics; increasing the awareness of the value of ANC and appropriate medical records and reporting of these viruses.

\section{Conclusions and recommendation}

The study found relatively low but significant average prevalence rates of HIV (0.71\%), HBV (1.57\%) and HCV (0.64\%) among the ANC attendees in Bauchi State, Nigeria. The study recommends for improved HIV, HBC and HCV screening services at the facilities through a robust health policy that will also provide for free screening of HBV and HCV at the facilities. There is also need to provide the appropriate medical records tools to capture complete data on these viruses at the various facilities. There should be sustained awareness through health education and advocacy at the ANC clinics and communities to highlight the value of ANC and the screening of these viruses. Further studies are needed to monitor the prevalence and co- infection of HIV, HBV and HCV among the pregnant women in Bauchi State.

\section{References}

1. Alter MJ. Epidemiology of viral hepatitis and HIV co-infection. J Hepatol 2006;44:S6-9.

2. Chang CC, Crane M, Zhou JL, et al. HIV and co-infections. Immunol Rev 2013;254:114-42.

3. Centers for Disease Control and Prevention. HIV/AIDS and Viral Hepatitis. Division of Viral Hepatitis and National Center for HIV/AIDS, Viral Hepatitis, STD, and TB Prevention, 2018. Available from: https://www.cdc.gov/hepatitis/ populations/ hiv.htm

4. Modjarrad K, Vermund SH. Effect of treating co-infections on HIV-1 viral load: a systematic review. Lancet Infect Dis 2010;10:455-63.

5. Centers for Disease Control and Prevention. HIV and Viral Hepatitis.. National Center for HIV/AIDS, Viral Hepatitis, STD, and TB Prevention. 2017. Available from: https://www.cdc.gov/hiv/pdf/library/factsheets/hiv-viralhepatitis.pdf

6. Rockstroh JK. Influence of viral hepatitis on HIV infection. J
Hepatol 2006;44:525-7.

7. Chandra N, Joshi N, Raju YSN, et al. Hepatitis B and/or C coinfection in HIV infected patients: A study in a tertiary care center from south India. Indian J Med Res 2013;138:950-4.

8. Benhammou V, Tubiana R, Matheron S, et al. HBV or HCV Coinfection in HIV-1-Infected Pregnant Women in France: Prevalence and Pregnancy Outcomes. J Acquir Immune Defic Syndr 2018;77:439-50.

9. Ahmad I. Prevalence of Hepatitis B and C Viral Infection Among Pregnant Women in Peshawar, Pakistan, Hepat Mon 2016;16:e36383.

10. Schweitzer A, Horn J, Mikolajczyk RT, et al. Estimations of worldwide prevalence of chronic hepatitis B virus infection: a systematic review of data published between 1965 and 2013. The Lancet 2015;386:1546-55.

11. Hanafiah KM, Groeger J, Flaxman AD, Wiersma ST. Global epidemiology of hepatitis $\mathrm{C}$ virus infection: new estimates of age-specific antibody to HCV seroprevalence. Hepatology 2013;57:1333-42.

12. World Health Organisation. HIV/AIDS: HIV and Hepatitis coinfections. 2018. Available from: http://www.who.int/hiv/topics/hepatitis/en/

13. Umego CF, Mboto CI, Mbim EN, et al. Epidemiology of Hepatitis B Virus Infection in South-South, Nigeria: A Review. Int STD Res Rev 2018;7:1-17.

14. Tremeau-Bravard A, Ogbukagu IC, Ticao CJ, Abubakar JJ. Seroprevalence of hepatitis B and C infection among the HIVpositive population in Abuja, Nigeria. Afr Health Sci 2012;12:312-7.

15. Odjimogho S, Agofure O, Okandeji-Barry ORA, Ibrahim ZL. Prevalence of hepatitis $\mathrm{B}$ and $\mathrm{C}$ among HIV/AIDS patients attending Bingham University Teaching Hospital Jos Plateau State Nigeria: A retrospective study. J Publ Health Epidemiol 2018;10:198-204.

16. Mohammed AI, JY, Okwong OK, Umar MS. Seroprevalence of HBV, HCV and HIV Among Voluntary Blood Donors at a Tertiary Hospital in Bauchi, Northeastern Nigeria. EJPMR 2017;4:80-85.

17. Jibrin YB, Kolo PM, Mohammed A, et al. Burden of hepatitis $\mathrm{B}$ and $\mathrm{C}$ infections among pregnant women in Bauchi, Northeastern Nigeria. Sub-Saharan Afr J Med 2016;3:188-93.

18. Center for Disease Control and Prevention. Principles of Epidemiology in Public Health Practice, Third Edition An Introduction to Applied Epidemiology and Biostatistics. 2012. Available from: https://www.cdc.gov/ophss/csels/dsepd/ss 1978/lesson3/section2.html

19. Wasley A, Alter M. Epidemiology of hepatitis C: geographic differences and temporal trends. Semin Liver Dis 2000;20:116

20. Perz JF, Farrington LA, Pecoraro C, Hutin YJF, Armstrong G.L. Estimated global prevalence of hepatitis $\mathrm{C}$ virus infection. In: Abstracts of the Infectious Diseases Society of America 42nd annual meeting, Boston, MA, September 2004.

21. Duru MU, Aluyi HSA, Anukam KC. Rapid screening for coinfection of HIV and HCV in pregnant women in Benin City Edo State, Nigeria. Afr Health 2009;9:137-42.

22. Centre for Disease Control and Prevention Blood borne Infectious Diseases: Hiv/Aids, Hepatitis B, Hepatitis C. 2016. Available form: http://www.cdc.gov/niosh/topics/ bbp/genres.html.

23. Favour O, Onah VO, Anikwe VC. Sero-epidemiology of Human Immunodeficiency Virus (HIV), Hepatitis B and C among pregnant women in Rural Communities of Abaji Area 
Council, Nigeria. TAF Prev Med Bull 2012;11:431-8.

24. Chanu I, Auwalu U, Muhammad Y, et al. Epidemiological Study of HCV and HIV Infections in Relation to Certain Demographic Factors Among the Ante-Natal Population Within Kaduna Metropolis, Nigeria. Int J Infect Dis Ther 2016;1:13-21.

25. Obi RK, Umeh SC, Okurede OH, Iroagba II. Prevalence of hepatitis B virus infection among pregnant women in an antenatal clinic in Port Harcourt, Nigeria. Afr J Clin Exp Microbiol 2006; 7:78-82.

26. Mc Mahon BJ, Alward WL, Hall DB. Acute hepatitis B virus infection: relation of age to the clinical expression of disease and subsequent development of the carrier state. J Infect Dis 1985; 151:599-603.

27. Kiire CF. The epidemiology and Prophylaxis of hepatitis B in Sub-Saharan Africa:A review from tropical and subtropical
Africa. Gut 1996;38:5-12.

28. Tremeau-Bravard A, Ogbukagu IC, Ticao CJ, Abubakar JJ. Sero-prevalence of hepatitis B and C infection among the HIVpositive population in Abuja, Nigeria. Afr Health Sci 2012;12:312-7.

29. Olokoba AB, Salawu FK, Danburam A, et al. Hepatitis B virus infection amongst pregnant women in North-Eastern Nigeria A call for action. Nig J Clin Pract 2011;14:10-3.

30. Buseri FI, Seiyaboh E, Jeremiah ZA. Surveying Infections among pregnant women in the Niger Delta, Nigeria. J Global Infect Dis 2010;2:203-11.

31. Oluboyo BO, Ugochukwu VI, Olubuyo AO, et al. Prevalence of Hepatitis B and C Viral infections in pregnant women attending ante-natal Clinic in Nnewi, Nigeria. Eur Sci J 2014;10:434-41. 